\title{
An exploratory examination of additional ground access trips generated
}

by airport 'meeter-greeters'.

\section{Dr Thomas Budd}

\section{Centre for Air Transport Management}

Cranfield University, UK 


\section{Abstract}

A significant share of airport passengers are accompanied to and/or from the airport by friends and relatives to wave them off or greet them when they land. At some airports the number of these 'meeter-greeters' can be substantial, which can have important ground access planning, economic and environmental implications for the airport operator. Yet this group have received comparatively little attention in either the academic or industry literature. Consequently, to some extent 'meetergreeters' have remained something of a 'hidden' element of ground access user. In an attempt to address this, the paper uses secondary data analysis of the UK CAA Passenger Survey Report to explore 'meeter-greeters' at five UK airports; Heathrow, Gatwick, Manchester, Stansted and Luton. Focus is given to assessing the scale of 'meeter-greeter' journeys and the role of a passenger's trip purpose (business/leisure) and resident status (resident/non-resident) in this process. A key finding from the analysis relates to the disproportionate impact of multi-person trips, where a number of different 'meeter-greeters' accompany a passenger to the airport. The implications of these findings are discussed and a number of recommendations for decision makers proposed. Namely, it is suggested that airport monitoring and assessment procedures should incorporate a measure of the additional trip generation by 'meeter-greeters' in order to present a more complete picture of the number of people accessing/egressing an airport.

\section{Key words}

Ground Access, Meeter-Greeters, Airports, Environment. 


\section{Introduction- the challenges associated with 'meeter-greeters'}

Increasing demand for air travel in recent years has meant growing numbers of people traveling to and from airports. Worldwide, it is estimated that each year over 3.3 billion passengers travel between the estimated 4,000 airports that support scheduled air services (ATAG, 2014). Accommodating current and future demand for air travel will require the sustained provision of safe, efficient, reliable and affordable ground access travel for passengers and other airport users. This can act as a key competitive advantage for airports and their related economies, both in terms of widening the airports' effective catchment area and the wider benefits afforded by improved connectivity to air travel (Budd et al. 2015). At major airports with very large (even national) catchment areas the scale of ground access travel can be considerable. For example, Coogan (2008) estimates that an airport handling 45 million passengers per year can generate up to 5 million vehicle miles of ground access travel per day (the equivalent of $1,825,000,000$ miles peryear).

In the UK, as elsewhere, ground access travel continues to be dominated by private vehicle trips. At the UK's two largest airports, Heathrow (73.1 million annual passengers) and Gatwick (37.9 million annual passengers), private vehicles represent $58.6 \%$ and $58.3 \%$ of the mode share, respectively (CAA, 2015). At smaller regional airports private vehicle mode shares are generally even higher, such is the case at Luton (70.9\% private vehicle), Manchester (83.5\% private vehicle) and Birmingham (76.5\% private vehicle) (CAA, 2015). Given that these trips are necessarily generated to/from a single site the implications in terms of traffic delays and congestion, as well as local air quality and human health, are profound (Budd et al. 2011a).

Many passengers travelling to/from airports will be accompanied by friends or relatives, who wish to either wave the passenger farewell or greet them on their arrival. At some airports the number of these 'meeter-greeters' can be significant. It has been suggested that this may be especially the case at airports that handle higher shares of international leisure passengers than those with a stronger focus on business traffic (LeighFisher et al., 2010). This is most likely a reflection of the differing trip 
characteristics of these journey types, namely that leisure passengers may be staying away for longer, travelling with luggage, and are unlikely to have their travel paid for (which will generally be the case for business passengers). The residence status of the passenger may also play a role in this, given that residents of a region are likely to have greater access to their network of friends and relatives (i.e. potential 'meeter-greeters') than passengers who are non-residents of a region. While potentially significant in scale and scope, the role of 'meeter-greeters' in a ground access context has not been widely examined or reported in the research.

Potential ground access problems may be exacerbated if the passenger chooses to be dropped-off or picked-up at the airport in a private vehicle. This is to say that the passenger is either droppedoff/picked-up at the terminal kerbside, or the vehicle is parked for a relatively short duration while the passenger is accompanied to/from the terminal building. In each case, up to four vehicle journeys are generated to and from the airport compared with two journeys if the passenger had parked their own vehicle at the airport for the duration of their trip. These additional vehicle journeys have the potential to increase congestion and associated environmental problems. Miyoshi and Mason (2013) found that drop-off/pick-up journeys produce a substantially greater volume of carbon dioxide per passenger kilometre $(229 \mathrm{~g} / \mathrm{pkm})$ than cars that are driven and parked at the airport $(75 \mathrm{~g} / \mathrm{pkm})$. The disproportionate environmental impact of drop-off/pickup trips is also supported by research by Budd et al. (2011b). In a series of interviews with ground access managers in the UK, it was noted by one manager at a major airport that while drop-off/pick-up accounted for only $20 \%$ of passengers journeys these trips represented $42 \%$ of the airports controllable carbon emissions.

In addition to potentially significant environmental impacts, an abundance of drop-off and pick-up journeys at an airport may have important financial implications both in terms of expenditure on monitoring, maintaining and policing terminal forecourt areas, but also lost potential car parking revenues. Although a number of airports have started charging a fee for vehicles to enter terminal 
forecourt areas, at many airports this is not charged for. Even where the vehicle is parked for a short period of time while the passenger is accompanied into the terminal building, the cost of this parking (i.e. short-stay) will generally be far lower than if the passenger had paid for their vehicle for the duration of their trip (i.e. long-stay). Given that car parking revenues are often the largest source of non-aeronautical revenue at an airport and can account for as much as a quarter of total revenues, the potential financial implications of this issue should not be underestimated (Jacobs Consultancy et al. 2009).

As a result, airport operators are increasingly seeking ways to reduce the share of drop-off and pickup journeys at their airport. An important focus of this has been trying to initiate behavioral change towards more sustainable forms of travel (i.e. to reduce private vehicle use while simultaneously increasing public transport use). For example, in 2007 Manchester Airport, UK stated in their Master Plan that "our ability to influence the travel behavior of both passengers and employees is critical to the success of our Ground Transport Plan" (Manchester Airport, 2007). Having said this, research suggests that there may be considerable barriers to achieving such goals. Budd et al. (2014) found that passengers who currently favoured being dropped-off/picked-up at the airport also showed considerable resistance to changing their behavior. This group, termed the 'Dogmatic Drop-Offs', were found to have strong attachments to using their car for ground access journeys, a low perception of the environmental problems associated with ground access travel, and subsequently exhibited very little potential to reduce their car use as a group.

Despite their significant impacts there has been comparatively little research into the nature and scale of 'meeter-greeters' at airports. This situation is arguably due to the lack of availability of relevant data, which in turn relates to the difficulties associated with establishing and maintaining suitable data collection and monitoring regimes. Traditionally, airports have relied on passenger mode choice information and traffic count data to monitor ground access travel. However, this can fail to take into account potentially important information about the number/type of vehicles 
associated with a particular passenger, the volume of traffic generated by particular flights or routes, or the make-up of the 'meeter-greeter' group accompanying the passenger to/from the airport. Consequently, there is a need to examine the nature of 'meeter-greeter' trips to airports and, following this, suggest ways for improving the way in which these trips are monitored and analysed in order to aid future airport strategic development.

To this end, the paper examines the nature and scale of airport 'meeter-greeters' at five UK airports in order to address two key objectives; to examine the scale of 'meeter-greeter trip' generation, and then to assess how the nature of these trips vary according to a passengers trip purpose and resident status. The following sections describes the study airports (Section 2) and data used (Section 3) in the study. This is followed by a description of the method (Section 4) and the results of the analysis (Section 5). The paper concludes with a discussion and condusion of the research findings (Section 6).

\section{Study Airports}

In order to assess 'meeter-greeter' trips at a range of airports it was considered important that the study airports varied in terms of their size, market position, and ground access. Consequently, 5 UK airports were selected for the study; Heathrow, Gatwick, Manchester, Stansted, and Luton. Table 1 provides a summary of the 5 study airports in terms of annual passengers handled, ground access mode share, access arrangements and share of business and leisure traffic.

Heathrow is the largest airport in the UK, and the UKs only true hub. In 2014 Heathrow handled 73.1 million passengers (CAA, 2015). By road, Heathrow is accessible via the busy M25 or M4 motorways. The airport is also a major public transport interchange, and is the busiest long distance passenger coach station in the UK. By rail the airport is served by the Picadilly Line of the London Underground, by local Heathrow Connect rail services and the Premium Heathrow express rail service that operates to/from London's Paddington Station. In 2014, 58.6\% of passengers accessed the airport by 
private vehicle. Proportionally, Heathrow has the highest share of business passengers $(29.6 \%)$ of the study airports.

Table 1. Summary of study airports

\begin{tabular}{|c|c|c|c|c|c|c|c|c|c|c|}
\hline & \multirow[t]{2}{*}{$\begin{array}{l}\text { Annual } \\
\operatorname{Pax}(\mathrm{m})\end{array}$} & \multirow[t]{2}{*}{$\begin{array}{l}\text { Leisure } \\
\text { (\%) }\end{array}$} & \multirow[t]{2}{*}{$\begin{array}{c}\text { Business } \\
(\%)\end{array}$} & \multicolumn{2}{|c|}{$\begin{array}{l}\text { Ground access } \\
\text { mode share (\%) }\end{array}$} & \multirow[t]{2}{*}{$\begin{array}{l}\text { Local } \\
\text { Bus }\end{array}$} & \multirow[t]{2}{*}{ Coach } & \multirow[t]{2}{*}{$\begin{array}{l}\text { Heavy or } \\
\text { Dedicated } \\
\text { Rail }\end{array}$} & \multirow{2}{*}{$\begin{array}{l}\text { Under- } \\
\text { ground, } \\
\text { Light } \\
\text { Rail or } \\
\text { Metro }\end{array}$} & \multirow{2}{*}{$\begin{array}{l}\text { Charge } \\
\text { for } \\
\text { drop- } \\
\text { off? }\end{array}$} \\
\hline & & & & Private & Public & & & & & \\
\hline Heathrow & 73.1 & 70.5 & 29.6 & 58.6 & 41.0 & & & & & No \\
\hline Gatwick & 37.9 & 86.1 & 13.9 & 58.3 & 41.4 & & & & & No \\
\hline Manchester & 21.7 & 82.1 & 17.9 & 83.5 & 16.2 & & & & $*$ & No \\
\hline Stansted & 19.9 & 84.8 & 15.2 & 48.5 & 49.6 & & & & & No \\
\hline Luton & 10.4 & 83.5 & 16.5 & 70.9 & 28.8 & & & $\begin{array}{ll} & * \\
* & \end{array}$ & & Yes \\
\hline
\end{tabular}

* Manchester Metro extension to the airport opened in 2015

** Linked to Luton Airport Parkwaystation by shuttle bus

Source: CAA, 2015.

The second largest airport in the UK, Gatwick, handled nearly 38 million passengers in 2014 (CAA, 2015). The airport is located close to the M23 motorway, and served by an extensive network of long distance coach services and local buses. By rail, the airport is served by a dedicated railway station on the Brighton to London Victoria main line. In 2014, 58.3\% of passengers accessed the airport by private vehicle. Gatwick is strongly characterised by leisure traffic, which accounts for $86.1 \%$ of their passengers.

Manchester Airport (21.7 million annual passengers) is the third largest airport in the UK, located in the north-west of England. While the airport is well served by both local buses and long distance coaches, and has a dedicated railway station, the private vehicle mode share (83.5\%) is considerably higher than at airports of a comparable size in the UK (CAA, 2015). The airport was recently 
connected to the Manchester Metro Light Rail system serving the City of Manchester. Leisure passengers account for $82.1 \%$ of all passengers at Manchester.

The fourth study airport, Stansted, is the fourth busiest in the UK (19.9 million annual passengers). It is a large base for low-cost carriers Ryanair and easyJet. As de Neufville (2006) notes, ground access planning at airports with a strong focus on low-cost carriers may be different from other airports. Namely, that cost considerations may undermine the potential success of 'traditional' fixed route public transport services, but instead favour more flexible rubber-tired high occupancy modes like bus rapid transit. The airport is located close to the M11 motorway, and has a dedicated rail station with routes serving London as well as cross country routes to nearby Cambridge, and further afield to the cities of Leicester and Birmingham. Stansted has one of the lowest private vehicle mode shares in the UK, $48.5 \%$ (CAA, 2015). Nearly $85 \%$ of passengers using the airport are travelling for leisure purposes.

Luton airport is the fifth largest airport in the UK, and is a major base for low-cost and charter operations. In 2014 the airport handled 10.4 million passengers, with $83.5 \%$ of these travelling for leisure purposes. The airport is located adjacent to the busy north-south M1 motorway, and is connected to the Midland Mainline railway at Luton Airport Parkway station (accessible from the terminal by shuttle bus). In $2014,70.9 \%$ of passengers accessed the airport by private vehicle. It was also the only airport in the study that charged passengers for being dropped off/picked-up outside the terminal building. As of December 2015 , vehicles were charged $£ 2.50$ for a maximum stay of 10 minutes at the terminal kerb side (equivalent to nearly \$4 US).

\section{Data Source}

The decision to focus on the UK was also to some extent a pragmatic one, based on the need for up to date, relevant and comparable data on airport 'meeter-greeters'. In the UK, the Civil Aviation Authority (CAA) annually publishes results from their survey of departing passengers at selected airports. Information relating to a wide range of factors including a passenger's journey purpose, 
ground access mode choice and trip duration is collected, along with socio-demographic variables. The information is used by the CAA for market assessment purposes, demand forecasting, planning airport facilities, as well as other strategic decisions. Top- level summary statistics from the reports are published online and made freely available by the CAA on an annual basis.

The CAA surveys operate all year round, with between 3,000 and 70,000 individual surveys collected at each airport depending on its size. The surveys follow a stratified sampling design (by carrier, route and quarter), and are then weighted to reflect actual traffic levels at the airport in question. Survey interviews are conducted in the gate room by teams of skilled interviewers, last for between 5-7 minutes, and contain around 30 questions. All passengers are eligible apart from children aged under 2 years old. Results are also weighted to reflect the two-way passenger process, as it is assumed that over the period of data collection departing and arriving passenegrs will exhibit the same charactertics.

Since 2010 the survey has included a question asking the passenger to state the number of people who accompanied them to the airport with the purpose of 'waving them off'. Although it is not possible to disssagregate the data at the passenger level without purchasing custom data sets from the CAA, the freely available top level data includes cross tabulations by airport, trip purpose, and resident status (i.e. variables reevant for this paper). While the airports included in the survey vary from year to year, typically at least the 5 largest airports in the UK are included. Between 2010 and 2014 the only airports to have been included in the survey each year were Heathrow, Gatwick, Manchester, Stansted and Luton.

\section{Method}

Analysis was based on published statistics from the CAA Passenger Survey reports from 2010 to 2014. Information relating to the proportion of passengers who were 'waved-off' at each of the five study airports, and the number of people who accompanied them to do this, was used to extrapolate the number of additional 'meeter-greeters' generated at each site. The size of an 
accompanying group in the survey is categorized as 0 up to 5 or more people. So, if $1 \%$ of passengers at an airport handling 1,000,000 ground access passengers each had 2 people accompanying them to the airport, for the purpose of the analysis it was assumed that collectively 20,000 'meeter greeters' were generated to the airport in question $(1,000,000 \div 100 \times 2$ people). This was then calculated for people who were accompanied by 3 people, 4 people and so on and then aggregated to form a total number of 'meeter-greeters'. As this was also reported according to the passenger's journey purpose (business/leisure) and resident status (resident/foreign), it was then possible to apply the same principle to establish how 'meeter-greeters' varied by passenger market segment. The number of 'meeter-greeters' was then expressed as a proportion of the total number of ground access passengers. This is important as it provides an indication of the efficiency of an airports ground access system, and allows for easier comparisons between sites.

While rather simplistic in nature, the methodology nonetheless represents one of the few attempts to quantify the extent of 'meeter-greeter' trip generation using an independently collected and verified data source. However, there are inevitable limitations to such an approach. Without access to the disaggregated passenger data it was not possible to tell which mode of transport the passenger or the accompanying party used to travel to the airport. Consequently, it is possible (although perhaps unlikely) that a passenger and their accompanying party all travelled to the airport by public transport, say, or that a passenger and their accompanying party all travelled separately using different modes. While experience and past research (see Budd et al. 2014) suggests that the vast majority of passengers being accompanied to/from airports are indeed driven by private cars, but this cannot be ascertained conclusively from the data available. While such information would have been desirable, it was not considered a major limitation here seeing as the analysis seeks to examine the scale of 'meeter-greeters' generally, rather than trip generation from any one mode perse. 


\section{Results}

The following section reports findings from the analysis. Section 5.1 addresses the volume of 'meeter-greeter' generation across the 5 study airports, while Section 5.2 examines the role of passenger trip purpose and residence status in this process.

\subsection{Volume of 'meeter-greeter' generation}

Initially, the volume of 'meeter-greeters' was calculated and expressed as a share of total passengers at each of the 5 study airports for the period 2010-2014 (see Table 2). At the aggregate level, it can be seen that in $2014,7,083,387$ 'meeter-greeters' were generated at the five study airports, equivalent to $4.3 \%$ of the total number of passengers handled. In comparison, in 2010 collectively the five airports handled $141,202,000$ passengers and generated 7,878,235 'meeter-greeters', which was equivalent to $5.5 \%$ of the total number of passengers. The trend continued up to 2014 .

Table 2. 'Meeter-greeters' and percentage of total passengers at five study airports, 2010-2014.

\begin{tabular}{|c|c|c|c|c|c|c|}
\hline & & 2010 & 2011 & 2012 & 2013 & 2014 \\
\hline \multirow[t]{3}{*}{ Heathrow } & Total passengers & $65,668,000$ & $69,222,000$ & $69,471,000$ & $72,232,000$ & $73,164,000$ \\
\hline & Meeter-greeters & $4,719,456$ & $5,191,333$ & $4,263,150$ & $3,979,728$ & $4,453,156$ \\
\hline & $\%$ of total & $7.2 \%$ & $7.5 \%$ & $6.1 \%$ & $5.5 \%$ & $6.1 \%$ \\
\hline \multirow[t]{3}{*}{ Gatwick } & Total passengers & $31,009,000$ & $33,273,000$ & $33,792,000$ & $34,963,000$ & $37,886,000$ \\
\hline & Meeter-greeters & $1,135,600$ & $1,128,870$ & 912,543 & 832,468 & 951,642 \\
\hline & $\%$ of total & $3.7 \%$ & $3.4 \%$ & $2.7 \%$ & $2.4 \%$ & $2.5 \%$ \\
\hline \multirow[t]{3}{*}{ Manchester } & Total passengers & $17,408,000$ & $18,674,000$ & $19,408,000$ & $20,387,000$ & $21,660,000$ \\
\hline & Meeter-greeters & $1,004,357$ & 896,357 & 816,054 & 735,005 & 795,872 \\
\hline & $\%$ of total & $5.8 \%$ & $4.8 \%$ & $4.2 \%$ & $3.6 \%$ & $3.7 \%$ \\
\hline \multirow[t]{3}{*}{ Stansted } & Total passengers & $18,471,000$ & $17,974,000$ & $17,410,000$ & $17,781,000$ & $19,899,000$ \\
\hline & Meeter-greeters & 674,622 & 394,703 & 815,605 & 188,650 & 688,176 \\
\hline & $\%$ of total & $3.7 \%$ & $2.2 \%$ & $4.7 \%$ & $1.1 \%$ & $3.5 \%$ \\
\hline \multirow[t]{3}{*}{ Luton } & Total passengers & $8,646,000$ & $9,401,000$ & $9,522,000$ & $9,592,000$ & $10,400,000$ \\
\hline & Meeter-greeters & 253,200 & 304,062 & 805,390 & 781,943 & 194,541 \\
\hline & $\%$ of total & $2.9 \%$ & $3.2 \%$ & $8.5 \%$ & $8.2 \%$ & $1.9 \%$ \\
\hline \multirow[t]{3}{*}{ Total } & Total passengers & $141,202,000$ & $148,544,000$ & $149,603,000$ & $154,955,000$ & $163,009,000$ \\
\hline & Meeter-greeters & $7,787,235$ & $7,915,325$ & $7,612,742$ & $6,517,794$ & $7,083,387$ \\
\hline & $\%$ of total & $5.5 \%$ & $5.3 \%$ & $5.1 \%$ & $4.2 \%$ & $4.3 \%$ \\
\hline
\end{tabular}


Although the overall number of passengers at the five study airports grew from 141,202,000 in 2011 to $163,009,000$ in 2014 , over the same period the number of 'meeter-greeters' fell slightly from $7,787,235$ to $7,083,387$. Proportionally this represented a decrease from $5.5 \%$ of all passengers in 2011, to $4.3 \%$ of all passengers in 2014.

At the individual airport level there was found to be considerable variation in terms of the nature of their 'meeter-greeter' generation. To aid fairer comparison between the different sites, the number of 'meeter-greeters' was represented as a share of the total number of ground access passengers. This intentionally excluded the role of connecting passengers who inevitably do not use the ground access system, and who were thought likely to play more of a role at the larger airports such as Heathrow. Nonetheless, by some distance Heathrow was found to have both the highest volume and overall share of 'meeter-greeters' of the study airports. In 2014, 'meeter-greeters' accounted for $4,453,156$ people travelling to Heathrow, equivalent to $9.4 \%$ of the total number of ground access passengers using the airport $(47,374,000)$. These figures represent a reduction from a peak of nearly 5.2 million 'meeter-greeters' in 2011 (11.3\% of ground access passengers). To put this into context, these figures are equivalent to the total number of air passengers handled by East Midlands Airport, the UK's 11th busiest airport, over the same period (CAA, 2015). In other words, the additional 'meeter-greeters' generated to and from Heathrow itself represents the size of a regional airport. Over the period 2010-2014 there was a small decline in both the volume and overall share of 'meeter-greeters' at Heathrow, down from 4,719,456 to 4,453,156 and $11.2 \%$ to $9.4 \%$, respectively. 


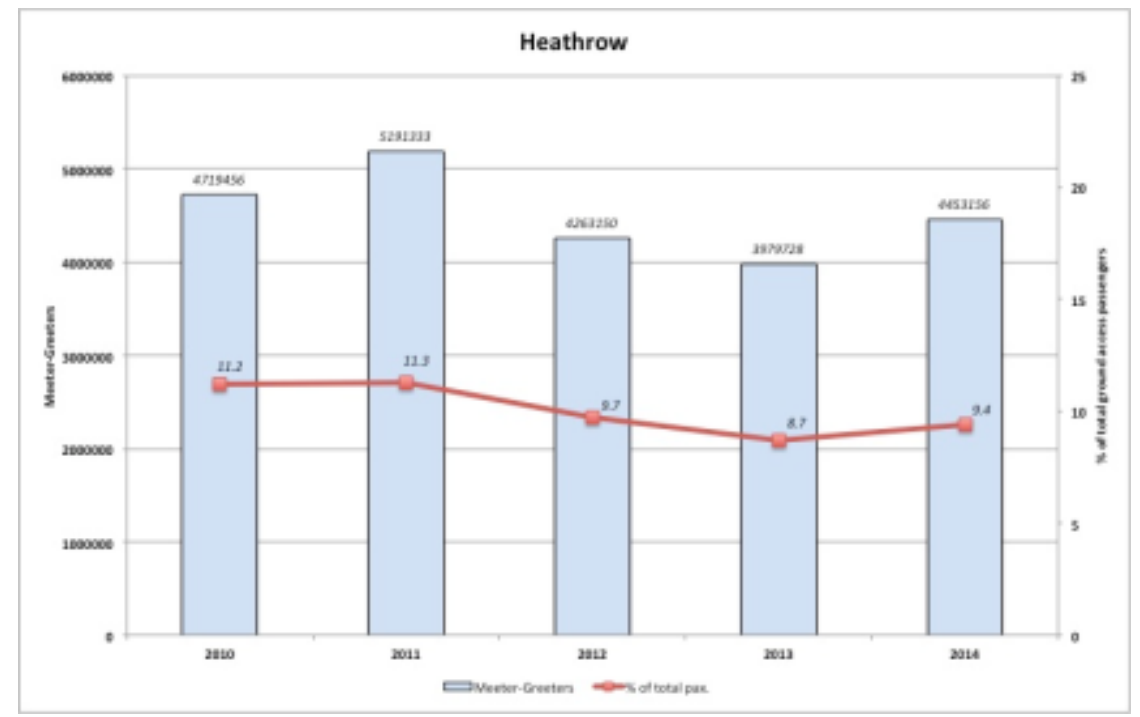

Figure 1. Volume and Share of 'meeter-greeters' at Heathrow Airport, 2010-2014

In comparison, Gatwick Airport, the other large airport included in the study, exhibited very different results (Figure 2). In 2014, 951,642 'meeter-greeters' were generated to Gatwick, which accounted for $2.7 \%$ of total ground access passengers $(28,390,000)$. Both the volume and share of 'meetergreeters' remained fairly stable over the five-year period, falling slightly from $1,135,600(4.0 \%)$ in 2010 to $951,642(2.7 \%)$ in 2014.

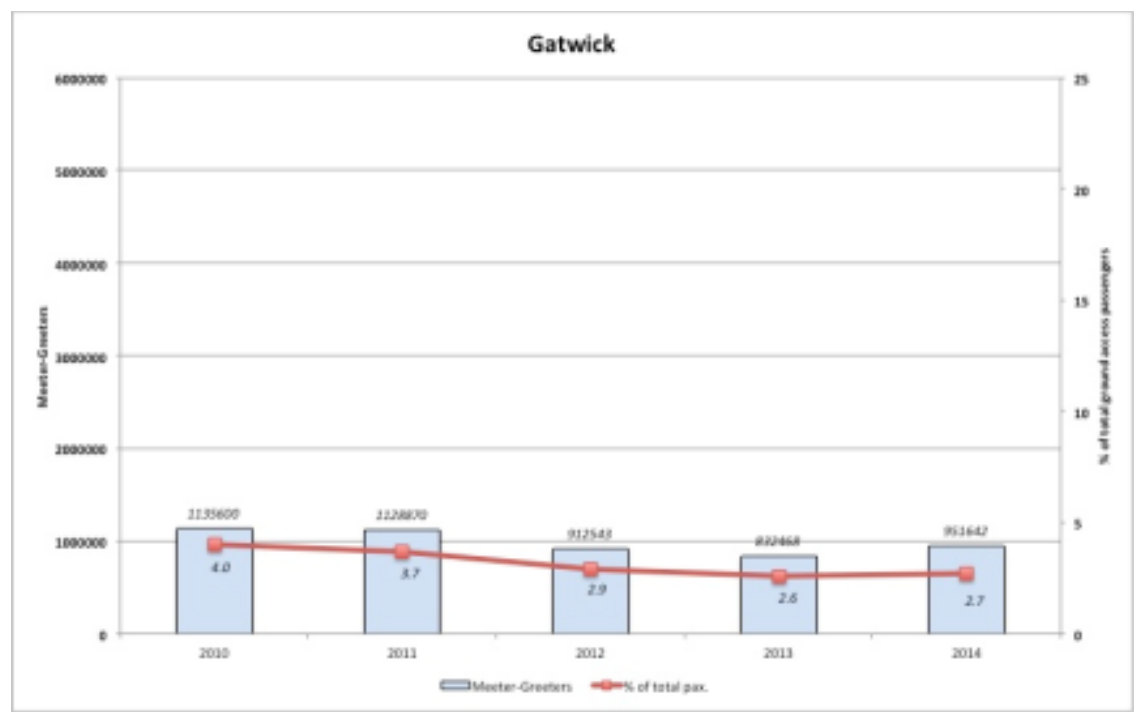

Figure 2. Volume and Share of 'meeter-greeters' at Gatwick Airport, 2010-2014 
While it was expected that the total volume of 'meeter-greeters' would be lower than Heathrow, given that Gatwick handles fewer passengers, it is notable the extent to which this is the case. While roughly half the size of Heathrow in terms of annual passengers handled (see Table 1), the volume of 'meeter-greeters' at Gatwick represents a fifth (21.4\%) of those at Heathrow. Proportionally, the share of 'meeter-greeters' to ground access passengers at Gatwick (2.7\% in 2014) is al so lower than at Heathrow (9.4\% in 2014). These findings are significant given that the two airports exhibit very similar mode shares, which suggest that it is unlikely that these findings are a result of variation in mode choice alone. Furthermore, it also suggests that using mode choice data alone as a means of estimating 'meeter-greeter' volumes may not always be that accurate.

Potential issues such as this are also shown when comparing the findings from Manchester and Stansted Airport (Figures 3 and 4). While similar in size in terms of the number of annual passengers handled (see Table 1), in terms of ground access mode share Manchester is strongly characterised by a dominance of private vehicle trips ( $83.5 \%$ in 2014). In contrast, Stansted has one of the lowest private vehide mode shares of any UK airport ( $48.5 \%$ in 2014). Yet, the profiles of the two airports in terms of the volume and share of 'meeter-greeters' generated are relatively similar. In 2014, 795,872 'meeter-greeters' were generated at Manchester Airport, equating to $3.8 \%$ of total

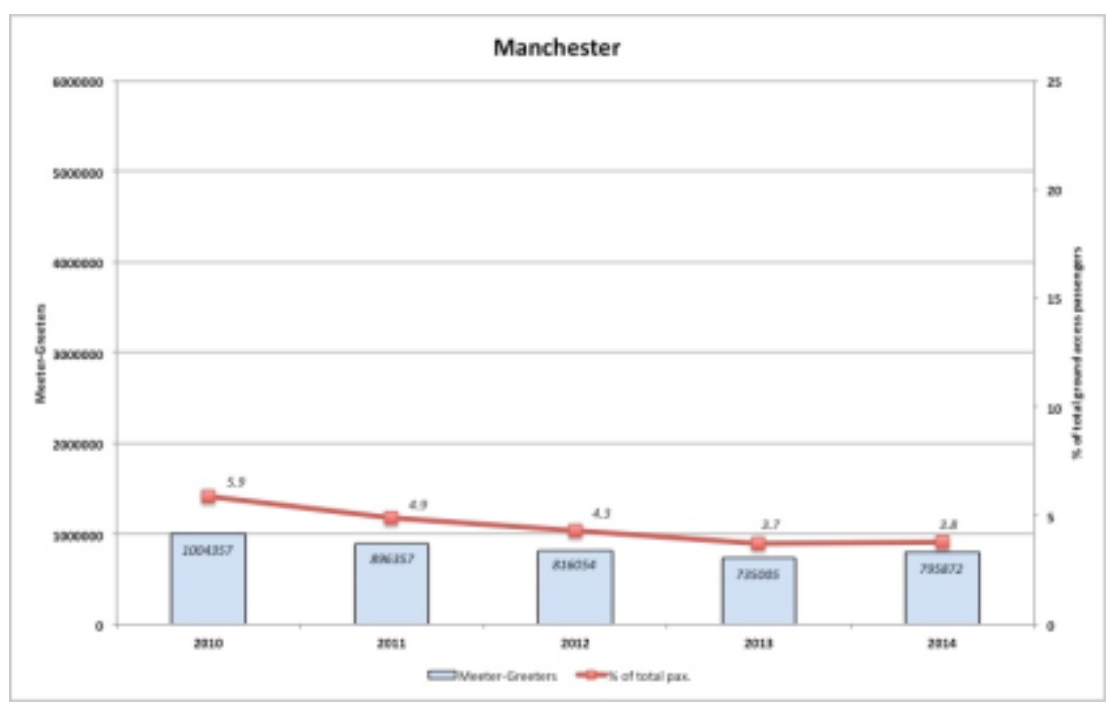

Figure 3. Volume and Share of 'meeter-greeters' at Manchester Airport, 2010-2014 


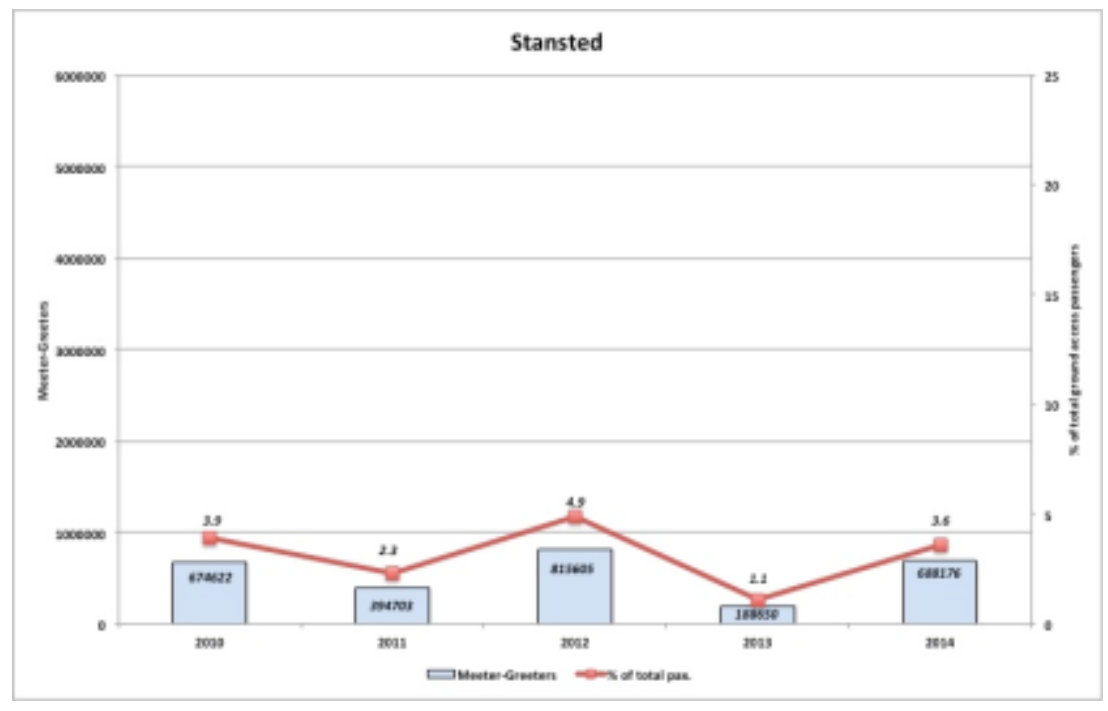

Figure 4. Volume and Share of 'meeter-greeters' at Stansted Airport, 2010-2014

ground access passengers $(20,944,000)$. In the same year, 688,176 'meeter-greeters' were generated at Stansted Airport, which reflected $3.6 \%$ of total ground access passengers $(19,116,000)$. It seems likely, therefore, that other factors relating to the nature of the of the passenger's trip, market characteristics of the airport, and othervariables play an important role in explaining this situation.

Unlike Heathrow, Gatwick and Manchester, where there appears to be a trend of a slight reduction (or at least plateauing) of 'meeter-greeter' generation over the last five years, Stansted appears to exhibit greater fluctuation. For example, in 2012 the volume of 'meeter-greeters' at Stansted peaked at $815,605(4.9 \%)$, before falling to $188,650(1.1 \%)$ in 2013 . A year later, this had risen again to $688,176(3.6 \%)$. It seems unlikely that this is solely a reflection of varying passenger numbers, given that the annual passengers numbers at Stansted grew over the same period from 16.9 million in 2012, to 19.1 million in 2014 (CAA 2013, 2014, 2015). Again, it would seem likely that other influencing factors are involved here.

A sharp fluctuation is also shown at Luton Airport (Figure 5). In 2010 and 2011, 'meeter-greeters' accounted for $253,200(3.0 \%)$ and 304,062 people (3.3\%), respectively. However, in 2012 the number of 'meeter-greeters' at the airport rose sharply to $805,390(8.6 \%)$ and remained at 781,943 
people (8.3\%) the following year. The increase is hard to explain given that the survey results did not indicate a similar fluctuation in either total passenger numbers or mode share over the same period.

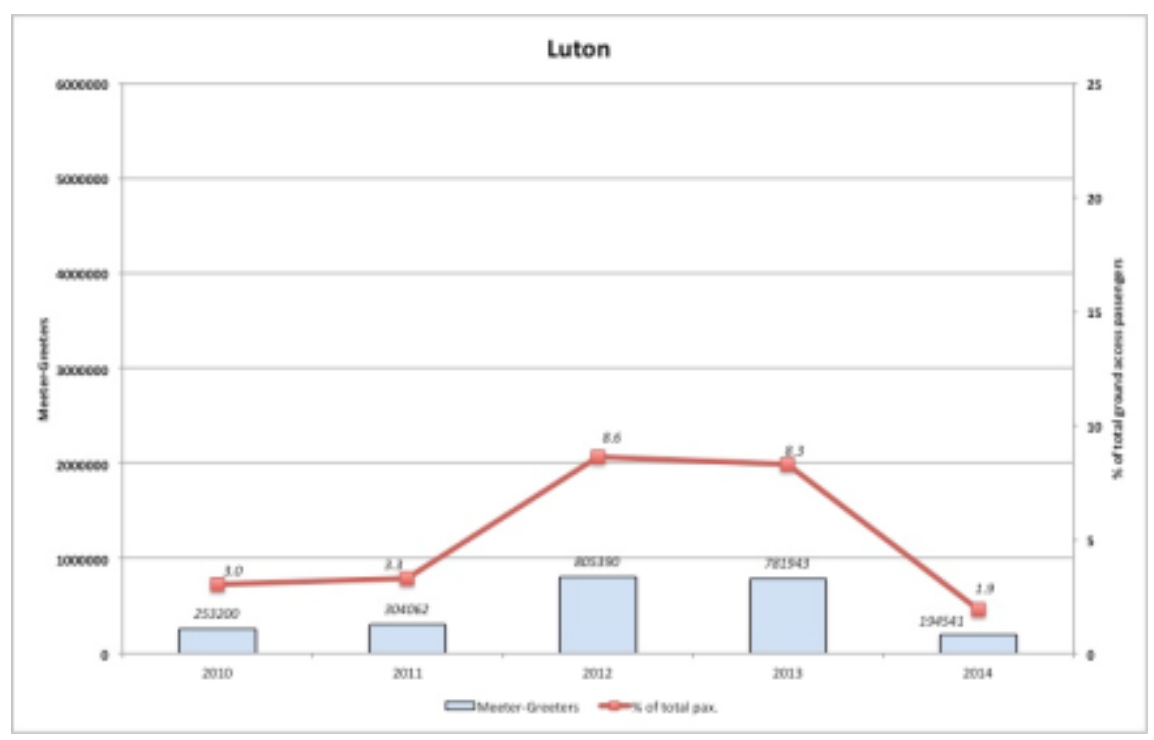

Figure 5. Volume and Share of 'meeter-greeters' at Luton, 2010-2014

Equally, it is notable that in 2014 there is then a considerable decline in 'meeter-greeters' to 194,541 (1.9\%), which is lower than the pre 2012 levels. As total passenger numbers at Luton increased over the same period (9.4 million in 2013 to 10.2 million in 2014), it is possible that this change is a reflection of specific policies implemented by the airport targeted at reducing drop-off/pick-up trips, although it is impossible to tell to what extent this is the case from the data alone.

One important aspect of the CAA survey data is that it provides an indication of the size of the party accompanying the passenger (i.e. how many 'meeter-greeters' accompanied each passenger). In simple terms, the larger the group size the more people the ground access system and airport facilities will need to accommodate at any particular time. Intuitively, if a passenger is accompanied by a number of different 'meeter-greeters' $(3,4$ or even 5 or more people) this will have a disproportion ground access impact than a passenger who is dropped-off/picked-up by only one or two people. Subsequently, analysis was conducted to examine the extent of these 'multi-person meeter-greeter trips' (seeTable 3). 
Table 3. Role of 'multi-person' meeter-greeter trips (i.e. 3 or more meeter-greeters) at the five study airports, 2010-2014.

\begin{tabular}{l|cc|cc|cc|cc|cc}
\hline & \multicolumn{2}{|c|}{$\mathbf{2 0 1 0}$} & \multicolumn{2}{|c|}{$\mathbf{2 0 1 1}$} & \multicolumn{2}{c|}{$\mathbf{2 0 1 2}$} & \multicolumn{2}{c|}{$\mathbf{2 0 1 3}$} & \multicolumn{2}{c}{$\mathbf{2 0 1 4}$} \\
\cline { 2 - 10 } & $\% p a x$ & $\% m-g$ & $\% p a x$ & $\% m-g$ & $\% p a x$ & $\% m-g$ & $\% p a x$ & $\% m-g$ & $\% p a x$ & $\% m-g$ \\
\hline Heathrow & 0.8 & 26.8 & 0.8 & 25.7 & 0.8 & 30.9 & 0.6 & 25.3 & 0.9 & 31.9 \\
Gatwick & 0.3 & 30.0 & 0.3 & 32.4 & 0.2 & 27.6 & 0.2 & 21.9 & 0.1 & 11.1 \\
Manchester & 0.6 & 35.6 & 0.6 & 44.9 & 0.4 & 34.9 & 0.4 & 40.5 & 0.3 & 31.6 \\
Stansted & 0.1 & 7.7 & 0.1 & 13.0 & 0.0 & 0.0 & 0.0 & 0.0 & 0.1 & 8.3 \\
Luton & 0.0 & 0.0 & 0.0 & 0.0 & 0.4 & 17.4 & 0.3 & 12.0 & 0.0 & 0.0 \\
\hline
\end{tabular}

$\%$ pax = percentage of ground access passengers

$\% \mathrm{~m}-\mathrm{g}=$ percentage of total meeter-greeters

As shown in Table 3, while only a relatively small proportion of ground access passengers have three or more 'meeter-greeters' accompanying them to the airport, these trips have a disproportionate impact in terms of the share of 'meeter-greeters'. For example, in 2014 at Heathrow $0.9 \%$ of ground access passengers were accompanied by 3 or more 'meeter-greeters'. Yet this group accounted for nearly a third (31.9\%) of all 'meeter-greeters' at the airport. Similarly, at Manchester the share of 'multi-person meeter-greeter' fell slightly from $0.6 \%$ of ground access passengers in 2010 , to $0.3 \%$ in 2014. However, this relatively small share of passengers still generated nearly a third of 'meetergreeters', albeit with a much lower total volume than at Heathrow.

At Gatwick, it is noticeable how the contribution of these 'multi-person meeter-greeter' trips fell from $30.0 \%$ of 'meeter-greeters' in 2010 , to $11.1 \%$ in 2014 . This could yield both positive and negative impacts for the airport depending on the situation. If proportionally fewer passengers chose to be dropped-off/picked-up in 2014 than in 2010, then this would likely yield environmental and financial benefits for the airport. However, seeing as the number of meeter-greeters at the airport remained fairly stable over this period (see Figure 2), it is possible that proportionally more passengers chose to be dropped-off/picked-up by a smaller number of meeter-greeters (i.e. average group size and may have decreased, but total drop-off/pick-up trips may have actually increased). 
At Stanted and Luton the role of 'multi-person meeter-greeter' trips appears much reduced compared with the other study airports. Having said this, it is perhaps significant that in 2012 and 2013 the share of multi-person trips at Luton rose to $0.4 \%$ and $0.3 \%$, respectively, which corresponds with the spike in the volume of 'meeter-greeters' at this time, as noted in Figure 5.

\subsection{The role of trip purpose and resident status}

A passenger's trip purpose and residence status have been shown to play an important role in ground access travel behaviour. To this end, analysis focused on examining how a passenger's trip purpose (business v leisure) and residence status (resident v foriegn) affected 'meeter-greeter' trip generation. Figure 6 shows the proportion of passengers in each of the four main market segments

(UK Business, UK Leisure, Foreign Business, and Foreign Leisure) who travelled with 'meetergreeters' at the five study airports in 2014.

While it was relatively difficult to draw valid comparisons between the study airports given the varying role played by each market segment at the airport in question, variations in 'meeter-greeter' trip generation were evident in the data. For example, at all 5 airports foreign leisure travellers were found to be the most likely to be travelling with at least 1 'meeter-greeter' (albeit at Gatwick, where this only amounted to $1.8 \%$ of this segment). At Heathrow, $7.8 \%$ of foreign leisure passengers travelled with at least 1 'meeter-greeter'. This was proportionally the highest of any 

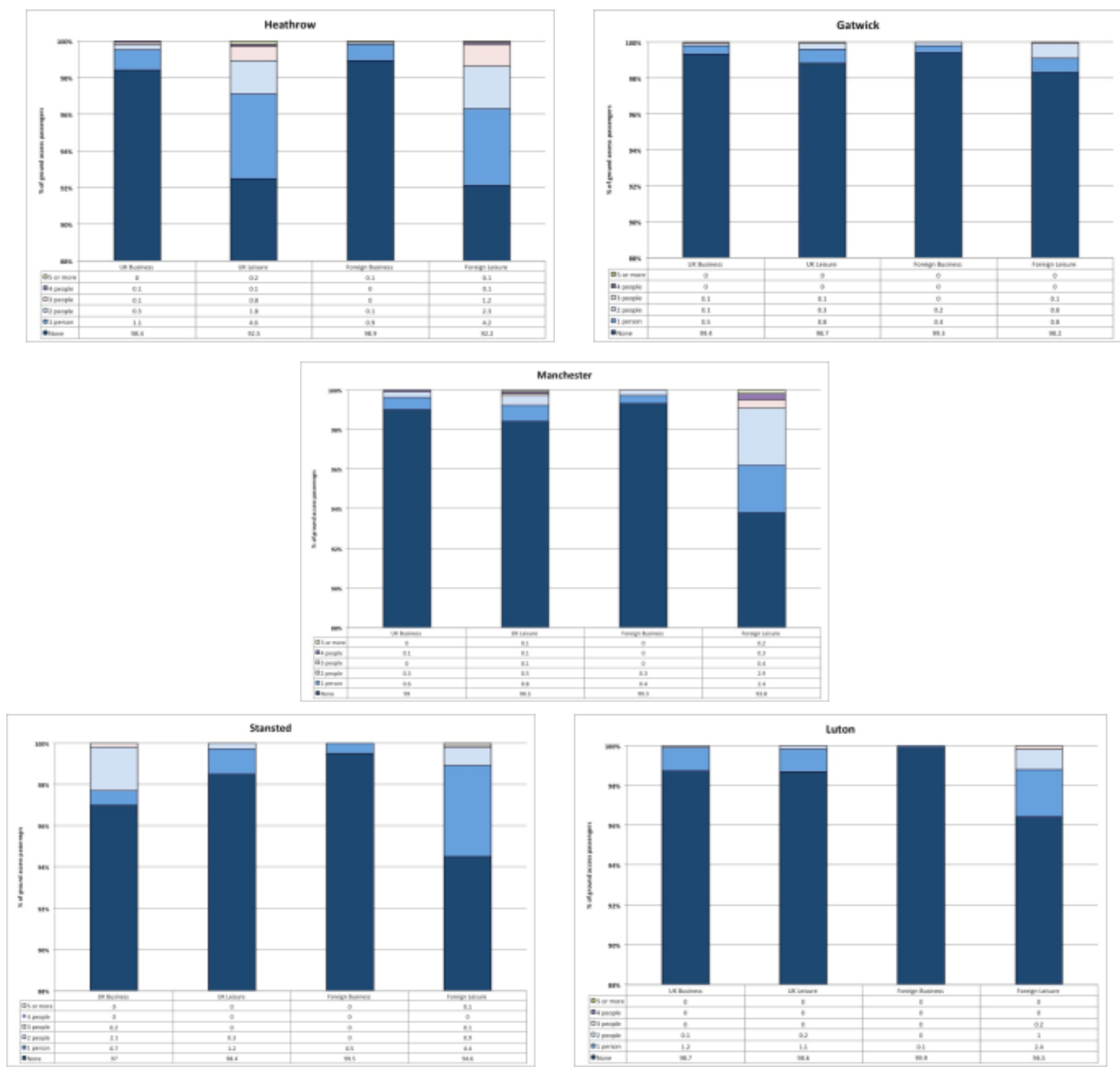

Figure 6. Share of passengers travelling with 'meeter-greeters' by market segment

market segment across the 5 study airports. Similarly, at Manchester (6.2\%), Stansed (5.4\%), Luton (3.5\%), and Gatwick (1.8\%), foreign leisure passengers were shown to be the most likely group to have travelled with at least one 'meeter-greeter.' Intuitively this makes sense, given that it is possible that foreign leisure passengers may be visiting the UK on holiday or to see friends or relatives. These passengers are unlikely to have use of a private car in the UK (unless one is hired), but they may be driven to/from the airport by their UK hosts. These passengers are perhaps also 
more likely to be travelling with luggage and in a group. They are also less likely to be familiar with local transport options, so may value the simplicity afforded by 'door-to-door' travel. In combination, these factors may make public transport less of an attractive option and increase the likelihood of being dropped-off/picked-up.

In contrast, UK based leisure passengers were generally less likely to have travelled with 'meetergreeters'. The exception to this was Heathrow, where UK leisure passengers exhibited very similar behavior to the foreign leisure traveller segment. While it is difficult to conclude this from the data alone, it may suggest that the factors associated with being a non-resident in a region are more influential in terms of choosing to be dropped-off/picked-up than those associated with travelling for leisure purposes.

Generally speaking, passengers travelling for business were less likely than leisure passenger to have 'meeter-greeters' accompanying them at the airport. This was the case for both UK business passengers and foreign business passengers. For example, at Heathrow only $1.6 \%$ of UK business passengers travelled with a 'meeter-greeter', while for foreign business passengers this figure was 1.1\%. Similar results were found at the other four study aimorts. Again, these findings would appear to be consistent with the nature of business travel generally. Namely, that these passengers are likely to have their trip paid for by their employer which may make a taxi, public transport or driving more attractive options. They are also less likely to be travelling with heavy luggage, which largely negates the need for easy and convenient 'door-to-door- transport of heavy bags. Business trips are also generally shorter in duration than leisure trips, so even if a passenger is travelling over a considerable distance, there is perhaps less of a predisposition for friends and family of the passenger to 'wave them off' seeing as the passengers will likely be returning in only a day or so. 


\section{Discussion and Conclusion}

The paper examines an important, yet largely under researched, area of air transport operations. Namely, by means of secondary analysis of freely available passenger survey data the paper provides one of the few attempts in the literature to quantify the role played by airport 'meeter-greeters' in a ground access context. While necessarily limited in scope and complexity given the relative lack of relevant data, if nothing else, the findings indicate that in some cases very large numbers of people travel to and from airports with the sole purpose of 'meeting and greeting' air passengers. For example, in the case of Heathrow it was found that the number of annual 'meeter-greeters' generated were equivalent in scale to the number of annual passengers handled at East Midlands Airport, the UKs $11^{\text {th }}$ busiest airport.

This inevitably has important implications in terms of 'additional' environmental impacts and congestion generated from ground access traffic at airports. While it is impossible to accurately quantify this impact in terms of emissions levels using the data presented here alone, given that key information relating to the 'meeter-greeters' trip (mode of transport used, journey origin and so on) is not available here, the extent of the issue is still highly apparent. Having said this, and as already mentioned, in all likelihood the vast majority of these journeys will be undertaken by private vehicle. Given that these drop-off/pick-up journeys produce a substantially greater volume of carbon dioxide per passenger kilometre $(229 \mathrm{~g} / \mathrm{pkm})$ than cars that are driven and parked at the airport $(75 \mathrm{~g} / \mathrm{pkm})$ or public transport (see Miyoshi and Mason, 2013), the potential environmental and congestion impacts are profound. The ability to quantify the environmental and congestion impacts of 'meetergreeter' trips should therefore form a key avenue for future research.

It is significant, then, that the additional trips made by 'meeter-greeters' remain largely unreported in a ground access context. While passenger mode share has long remained the key performance metric in ground access monitoring and assessment, the statistic fails to take into account the significant volumes of 'hidden' additional travel from this group. It is therefore important that 
airport operators examine ways in which the full extent of 'meeter-greeter' journeys could be more accurately measured and recorded in data collection and monitoring procedures. This could aid formulation of more appropriate performance metrics and indicators, which in turn could enhance strategic development and foster improved target setting, monitoring and assessment of these journeys.

This issue is especially important considering planning of future airport facilities and key infrastructure. While projects are typically couched in terms of the number of passengers accommodated, it is important to consider that in some cases this will not represent the 'true' impact of these facilities in terms of likely ground access provision. This is an issue both in terms of the total number of 'meeter-greeters', but also in terms of accommodating their varying travel requirements and behavior, which may differ from other airport users. For example, 'meetergreeters' may drop-off a passenger at the terminal kerb side but then proceed to an airport car park in order to park their vehicle in order to join the passenger in the terminal building later. This may require the vehicle to leave and then re-enter the airport site in order to access the chosen car park. Similarly, problems may arise where 'meeter-greeters' arrive at the airport early to meet an arriving passenger, but do not wish to pay for short-term car parking. To some extent this is already seen where pre-booked taxis wait on surrounding access roads for their fare to arrive. At peak times, when capacity in the system may already be stretched, seemingly minor issues such as these may take on much greater significance.

When considering these issues, the lack of availability of relevant information and data relating to drop-off and pick-up journeys is apparent. Perhaps most notably there is a need for a more detailed examination and understanding of mode choice among passengers who are dropped-off at the airport and the 'meeter-greeters' who accompany them. As already noted, while past research and experience suggest that the majority of passengers are dropped-off by private vehicle, this could not be ascertained conclusively from the data available. Additionally, there is a need for comprehensive data relating to the vehicle occupancy of passengers who are dropped-off/picked-up at the airport. 
Clearly, the ground access implications of a passenger accompanied by 4 people travelling in 1 vehicle are very different than if the same 4 people arrived at the airport each travelling alone in separate vehicles. Availability of such information would benefit comprehension of these phenomena substantially. In this sense regulatory or public bodies such as the CAA could also have an important role to play in that, where possible, they could potentially make more information of this nature available in order to stimulate and aid future research in this field.

While there remains comparatively little published research on drop-off/pick-up journeys and 'meeter-greeters', the paper has highlighted two areas that may warrant future investigation. Certainly, the role of 'multi-person meeter-greeter' trips, where three or more people accompany a passenger, could represent an important avenue for future research given their disproportionate impact in terms of generation of 'meeter-greeters'. This could have both important environmental and economic implication for an airport depending on the specific situation. For example, a capacity constrained or congested airport may wish to limit the number of people accessing the airport site, whereas in other cases there may be financial benefits associated with attracting additional airport users in terms of increased retail spend or potential car parking revenue. Furthermore, analysis examining the role of a passenger's trip characteristics could be extended to include additional variables and/or applied at the individual route or flight level. This could help aid more detailed, fine grained forecasts of ground access behavior, allowing for forecasts to be made about the likely impacts of alterations to flight schedules, new services or routes. For example, if it were known that a particular flight or route generated large volumes of additional meter-greeter traffic, the flight in question could perhaps be scheduled so as not to exacerbate existing peaks in ground access traffic. In conclusion, while the present study is necessarily limited to some extent by the data available, it nonetheless represents a valid initial exploration of an important air transport issue which warrants further research and attention. 


\section{References}

ATAG (Air Transport Action Group)., 2014. Aviation Benefits Beyond Borders, Geneva.

Budd, T., Ison, S., Ryley., 2011a. Airport Surface Access Management: Issues and Policies, Journal of Airport Management, 6(1), 1-18.

Budd, T., Ison, S., and Ryley, T., 2011b. Airport Surface Access in the UK: A management perspective, Research in Transportation Business and Management, 1(1), 109-117.

Budd, T., Ryley, T., and Ison, S., 2014. Airport ground access and private car use: a segmentation analysis, Journal of Transport Geography, 36, 106-115.

Budd, T., Ryley, T., and Ison, S (2014) Airport ground access and private car use: a segmentation analysis, Journal of Transport Geography, 36(1), 106-115.

Budd, L., Ison, S., and Budd, T., 2015. Improving the environmental performance of Airport Surface Access in the UK: the role of public transport, Conference Presentation at Thredbo 2015:

International Conference Series on Competition and Ownership in Land Passenger Transport, Santiago, Chile.

Civil Aviation Authority (CAA)., 2013. Main Outputs of Reporting Airports 1986-2012 [online], available at:

www.caa.co.uk/docs/80/airport_data/2012Annual/Table_02_1_Main_Outputs_Of_UK_Airports_20 12.pdf, accessed 14/02/15. 
Civil Aviation Authority (CAA)., 2011. CAA Passenger Survey Report 2010, https://www.caa.co.uk/uploadedFiles/CAA/Content/Standard_Content/Data_and_analysis/Datasets /Passenger_survey/CAA\%20Passenger\%20survey\%20report\%202010.pdf, accessed 11/12/15.

Civil Aviation Authority (CAA)., 2012. CAA Passenger Survey Report 2011, [online], https://www.caa.co.uk/uploadedFiles/CAA/Content/Standard_Content/Data_and_analysis/Datasets /Passenger_survey/CAA\%20Passenger\%20survey\%20report\%202011.pdf, accessed 10/01/15.

Civil Aviation Authority (CAA)., 2013. CAA Passenger Survey Report 2012, [online], available at: http://www.caa.co.uk/docs/81/2012CAAPaxSurveyReport.pdf, accessed 11/12/15.

Civil Aviation Authority (CAA)., 2014. CAA Passenger Survey Report 2013, [online], available at: http://www.caa.co.uk/docs/81/2013CAAPaxSurveyReport.pdf, accessed 11/12/15.

Civil Aviation Authority (CAA)., 2015. CAA Passenger Survey Report 2014, [online], available at: http://www.caa.co.uk/uploadedFiles/CAA/Content/Standard_Content/Data_and_analysis/Datasets/ Passenger_survey/CAA\%20Passenger\%20Survey\%20Report\%202014.pdf, accessed 11/12/15.

Coogan, M. A., MarketSense Consulting LCC., and Jacobs Consultancy., 2008. Ground Access to Major Airports by Public Transportation, ACRP (Airport Cooperative Research Programme) Report 4, Transportation Research Board of the National Academies, Washington, D.C.

De Neufville, R., 2006. Planning Airport Access in an Era of Low-Cost Airlines, Journal of American Planning Association, 72(3), 2006.

LeighFisher, Dowling Associates Inc., JD Franz Rsearch Inc., and WILTEC, 2010. Airport Curbside and Terminal Area Roadway Operations, Airport Cooperative Research Programme (ACRP) Report 40, Transportation Research Board of the National Academies, Washington D.C. 
Jacobs Consultancy, Walker Parking Consultants, Mannix Group., and DMR Consulting., 2009. Guidebook for evaluating airport parking strategies and supporting technologies, ACRP (Airport Cooperative Research Programme) Report 24, Transportation Research Board of the National Academies, Washington D.C.

Manchester Airport., 2007. Ground Transport Plan: Part of the Manchester Airport Master Plan to 2030, Manchester Airport.

Miyoshi, C., and Mason, K., 2013. The damage cost of carbon dioxide emissions produced by passengers on airport surface access: the case of Manchester Airport, Journal of Transport Geography, 28, 137-143. 
2016-04-24

\title{
An exploratory examination of additional
} pÿground access trips generated by airport meete

\author{
Budd, Tom
}

Elsevier

Thomas Budd, An exploratory examination of additional ground access trips generated by

pÿairport meeter-greeters , Journal of Air Transport Management, Volume 53, June 2016, Pages 242-251

http://dx.doi.org/10.1016/j.jairtraman.2016.03.012.

Downloaded from Cranfield Library Services E-Repository 